MSC 35G05, 35G16, 47D09, 60H30

DOI: $10.14529 / \mathrm{mmp} 180308$

\title{
MULTIPOINT INITIAL-FINAL PROBLEM FOR ONE CLASS OF SOBOLEV TYPE MODELS OF HIGHER ORDER WITH ADDITIVE "WHITE NOISE"
}

\author{
G.A. Sviridyuk ${ }^{1}$ A.A. Zamyshlyaeva ${ }^{1}$, S.A. Zagrebina ${ }^{1}$ \\ ${ }^{1}$ South Ural State University, Chelyabinsk, Russian Federation \\ E-mail: sviridyuk@susu.ru, zamyshliaevaaa@susu.ru, zagrebinasa@susu.ru
}

Sobolev type equations theory has been an object of interest in recent years, with much attention being devoted to deterministic equations and systems. Still, there are also mathematical models containing random perturbation, such as white noise. A new concept of "white noise", originally constructed for finite dimensional spaces, is extended here to the case of infinite dimensional spaces. The main purpose is to develop stochastic higherorder Sobolev type equations theory and provide some practical applications. The main idea is to construct "noise" spaces using the Nelson-Gliklikh derivative. Abstract results concerning initial-final problems for higher order Sobolev type equations are applied to the Boussinesq-Love model with additive "white noise". We also use well-known methods in the investigation of Sobolev type equations, such as the phase space method, which reduces a singular equation to a regular one, as defined on some subspace of the initial space.

Keywords: Sobolev type equation; propagator; "white noise"; Wiener K-process; multipoint initial-final problem.

\section{Dedicated to Professor Jan Kisyniski on the occasion of his 85th birthday.}

\section{Introduction}

Sobolev type equations make up a vast area of nonclassical equations of mathematical physics. Their systematic study started in the middle of the twentieth century with the seminal work of S.L. Sobolev, though many such equations had been studied earlier on; we recall, in particular, the famous Navier-Stokes equation system (see the excellent review in [1]). Recently, there has been a major increase in the research of Sobolev type equations. We should mention several monographs about these problems [2-7]. Different aspects of the incomplete higher-order Sobolev type equations

$$
A u^{(n)}=B u+g,
$$

with the assumption ker $\mathrm{A} \neq\{0\}$, have been studied [8-11]. Here the operators $A, B \in$ $\mathcal{L}(\mathfrak{U} ; \mathfrak{F})$ (i.e. linear and continuous), $\mathfrak{U}$ and $\mathfrak{F}$ are Banach spaces, absolute term $g=g(t)$ models the external force, and $n \geq 2$ is a natural number. One of the prototypes of equation (1) is

$$
(\lambda-\Delta) v_{t t}=\alpha \Delta v+g
$$

which models, among others, the incompressible fluid free surface perturbation under the assumption of motion potentiality and conservation of mass in a layer [12], longitudinal vibrations of an elastic rod [13] and wave processes in smectic and plasma [14].

The shortcoming of the model (2) with the deterministic absolute term is that in natural experiments the system is exposed to random perturbation, for example in the form 
of white noise. Stochastic ordinary differential equations with different additive random processes (i.e. not only white noise, but more general Markov and diffusion processes) are now actively studied [15]. The traditional Ito-Stratonovich-Skorohod approach is the most widely followed, although new and very promising avenues of research have recently appeared $[11,16]$.

The first results concerning stochastic Sobolev type equations of the first order can be found in [17]. They are based on the extension of the Ito-Stratonovich-Skorokhod method to partial differential equations (see, for example, [18-20]). In this paper, the stochastic higher order Sobolev type equation

$$
A \eta^{(n)}=B \eta+N w
$$

is considered. Here, $w$ in the right hand side denotes the random process. It is required to find the random process $\eta(t)$, satisfying (in some sense) equation (3) and the multipoint initial-final conditions

$$
P_{j}\left(\eta^{(k)}\left(\tau_{j}\right)-\xi_{j}^{k}\right)=0, \quad j=\overline{0, m}, k=\overline{0, n-1},
$$

where $\tau_{j} \in \mathbb{R}$ with $\tau_{j}<\tau_{j+1}, j=\overline{0, m}, \xi_{j}^{k}, k=\overline{0, n-1}$, are given random variables, and $P_{j}$ are the relatively spectral projectors.

At first, $w$ was understood as white noise, which is a generalized derivative of the Wiener process. Later, a new approach to the investigation of equation (3) appeared [15] and is being actively developed [16,21-23], where "white noise" means the NelsonGliklikh $[15,24]$ derivative of the Wiener process. This "white noise" was first used in optimal measurement theory [25,26], which constructs a special space of "noises". The concept of "white noise" in this theory (that is, only in the finite dimensional spaces) proved to be highly efficient, therefore suggesting to extend the concept to infinite-dimensional spaces $[17,27]$. The main goal of this extension is to develop a theory of stochastic Sobolev type equations and its applications to nonclassical models of mathematical physics of practical importance [28].

Besides the introduction, the paper consists of three sections. The first one deals with the deterministic inhomogeneous linear Sobolev type equation of higher order. We define a multipoint initial-final problem and state a theorem on the existence of a unique solution. We borrowed results from $[10,29]$ and therefore give them without proofs. The second section extends the deterministic results of the first one to the stochastic setup by analogy with [23]; sketches of proofs complement the results. In the third section we consider the linear stochastic Boussinesq-Love equation. In conclusion, we outline possible directions for further research.

\section{A Deterministic Linear Sobolev Type Equation of Higher Order with Relatively $p$-Bounded Operators}

Let $\mathfrak{U}$ and $\mathfrak{F}$ be separable Hilbert spaces, operators $A, B \in \mathcal{L}(\mathfrak{U} ; \mathfrak{F})$. Following [18], introduce an $A$-resolvent set

$$
\rho^{A}(B)=\left\{\mu \in \mathbb{C}:(\mu A-B)^{-1} \in \mathcal{L}(\mathfrak{F} ; \mathfrak{U})\right\}
$$

and an $A$-spectrum $\sigma^{A}(B)=\mathbb{C} \backslash \rho^{A}(B)$ of operator $B$. The operator-functions $(\mu A-$ $B)^{-1}, R_{\mu}^{A}(B)=(\mu A-B)^{-1} A, L_{\mu}^{A}(B)=A(\mu A-B)^{-1}$ with the domain $\rho^{A}(B)$ are called 
the $A$-resolvent, the right and the left $A$-resolvents of operator $B$ correspondingly. If the set $\sigma^{A}(B)$ is bounded (i.e. there exists $a>0:|\mu|<a$ for all $\mu \in \sigma^{A}(B)$ ) then the operator $B$ is called $(A, \sigma)$-bounded.

Let the operator $B$ be $(A, \sigma)$-bounded, $p \in\{0\} \cup \mathbb{N}$. Construct the set $\sigma_{n}^{A}(B)=\{\mu \in$ $\left.\mathbb{C}: \mu^{n} \in \sigma^{A}(B)\right\}$; it is compact in $\mathbb{C}$ due to the compactness of the $A$-spectrum of operator $B$. Take the contour $\gamma=\left\{\mu \in \mathbb{C}:|\mu|=r, r^{n}>a\right\}$ that bounds the domain containing the points of $\sigma_{n}^{A}(B)$ and construct the projectors

$$
P=\frac{1}{2 \pi i} \int_{\gamma} \mu^{n-1} R_{\mu^{n}}^{A}(B) d \mu \in \mathcal{L}(\mathfrak{U}), \quad Q=\frac{1}{2 \pi i} \int_{\gamma} \mu^{n-1} L_{\mu^{n}}^{A}(B) d \mu \in \mathcal{L}(\mathfrak{F}) .
$$

Here, $R_{\mu^{n}}^{A}(B)=\left(\mu^{n} A-B\right)^{-1} A$ and $L_{\mu^{n}}^{A}(B)=A\left(\mu^{n} A-B\right)^{-1}$. Set $\mathfrak{U}^{0}\left(\mathfrak{U}^{1}\right)=\operatorname{ker} P(\operatorname{im} P)$, $\mathfrak{F}^{0}\left(\mathfrak{F}^{1}\right)=\operatorname{ker} Q(\operatorname{im} Q)$. Thus, the spaces $\mathfrak{U}$ and $\mathfrak{F}$ can be decomposed into direct sums $\mathfrak{U}=\mathfrak{U}^{0} \oplus \mathfrak{U}^{1}$ and $\mathfrak{F}=\mathfrak{F}^{0} \oplus \mathfrak{F}^{1}$, whereas $\mathfrak{U}^{0} \supset$ ker $A$. By $A_{k}\left(B_{k}\right)$ define the restriction of operator $A(B)$ onto $\mathfrak{U}^{k}, k=0,1$.

Lemma 1. [10] The operators $A_{k}, B_{k} \in \mathcal{L}\left(\mathfrak{U}^{k} ; \mathfrak{F}^{k}\right), k=0,1$, moreover, there exist the operators $B_{0}^{-1} \in \mathcal{L}\left(\mathfrak{F}^{0} ; \mathfrak{U}^{0}\right)$ and $A_{1}^{-1} \in \mathcal{L}\left(\mathfrak{F}^{1} ; \mathfrak{U}^{1}\right)$.

Construct the operators $H=B_{0}^{-1} A_{0} \in \mathcal{L}\left(\mathfrak{U}^{0}\right), S=A_{1}^{-1} B_{1} \in \mathcal{L}\left(\mathfrak{U}^{1}\right)$.

The $(A, \sigma)$-bounded operator $B$ is called $(A, p)$-bounded, $p \in\{0\} \cup \mathbb{N}$, if $\infty$ is a removable singular point (i.e. $H \equiv \mathbb{O}, p=0$ ) or a pole of order $p \in \mathbb{N}$ (i.e. $H^{p} \neq \mathbb{O}$, $\left.H^{p+1} \equiv \mathbb{O}\right)$ of the A-resolvent $(\mu A-B)^{-1}$ of operator $B$.

Introduce the following condition:

$$
\left.\begin{array}{c}
\sigma^{A}(B)=\bigcup_{j=0}^{m} \sigma_{j}^{A}(B), \text { for } m \in \mathbb{N} ; \text { moreover, } \sigma_{j}^{A}(B) \neq \emptyset, \\
\text { there exists a closed contour } \gamma_{j} \subset \mathbb{C} \text {, bounding a domain } \\
\qquad D_{j} \supset \sigma_{j}^{A}(B), \text { such that } \overline{D_{j}} \cap \sigma_{0}^{A}(B)=\emptyset \text { and } \\
\overline{D_{k}} \cap \overline{D_{l}}=\emptyset \text { for all } j, k, l=\overline{1, m} \text { with } k \neq l .
\end{array}\right\}
$$

Then we have

Lemma 2. [10] If the operator $B$ is $(A, \sigma)$-bounded and condition $(A)$ is fulfilled then

(i) there exist relatively spectral projectors

$$
\begin{aligned}
& P_{j}=\frac{1}{2 \pi i} \int_{\gamma_{j}} \mu^{n-1} R_{\mu^{n}}^{A}(B) d \mu \in \mathcal{L}(\mathfrak{U}), \quad j=\overline{1, m}, \\
& Q_{j}=\frac{1}{2 \pi i} \int_{\gamma_{j}} \mu^{n-1} L_{\mu^{n}}^{A}(B) d \mu \in \mathcal{L}(\mathfrak{F}), \quad j=\overline{1, m} .
\end{aligned}
$$

Moreover,

(ii) $P_{j} P=P P_{j}=P_{j}, Q_{j} Q=Q Q_{j}=Q_{j}$;

(iii) $P_{k} P_{l}=P_{l} P_{k}=\mathbf{O}$ for all $k, l=\overline{1, m}$ with $k \neq l$. 
Put $P_{0}=P-\sum_{j=1}^{m} P_{j} \in \mathcal{L}(\mathfrak{U}), Q_{0}=Q-\sum_{j=1}^{m} Q_{j} \in \mathcal{L}(\mathfrak{F})$. Due to Lemma 3 operators $P_{0}, Q_{0}$ are projectors. Moreover, $P_{j} P_{0}=P_{0} P_{j}=\mathbb{O}, Q_{j} Q_{0}=Q_{0} Q_{j}=\mathbb{O}$ for $j=\overline{1, m}$.

Thus, assume that condition (A) is fulfilled. Fix $\tau_{j} \in \mathbb{R}$ with $\tau_{j}<\tau_{j+1}$, vectors $u_{j} \in \mathfrak{U}$ for $j=\overline{0, m}$, and vector-function $f \in C^{\infty}(\mathbb{R} ; \mathfrak{F})$. Consider the linear inhomogeneous Sobolev type equation

$$
A u^{(n)}=B u+f .
$$

Refer to a vector-function $u \in C^{\infty}(\mathbb{R} ; \mathfrak{U})$ satisfying (5) as a solution to (5). Refer to a solution $u=u(t)$ to (5) satisfying the conditions

$$
P_{j}\left(u^{(k)}\left(\tau_{j}\right)-u_{j}^{k}\right)=0, \quad j=\overline{0, m}, k=\overline{0, n-1},
$$

as a solution to the multipoint initial-final value problem (6) for (5).

Introduce the following operator families

$$
U_{j}^{k}(t)=\frac{1}{2 \pi i} \int_{\gamma_{j}} \mu^{n-k-1}\left(\mu^{n} A-B\right)^{-1} A e^{\mu t} d \mu,
$$

$k=0,1, \ldots, n-1, j=1, \ldots, m$.

Lemma 3. [10] If the operator $B$ is $(A, p)$-bounded and condition $(A)$ is fulfilled then

(i) $U_{j}^{k}(t) k=0,1, \ldots, n-1, j=1, \ldots, m$ are propagators of homogeneous $(f \equiv 0)$ equation (5);

(ii) $\left(U_{j}^{k}(t)\right)_{t}^{(l)}=U_{j}^{k-l}(t)$ for $k=0,1, \ldots, n-1, j=0,1, \ldots, m, l=0,1, \ldots, k$;

(iii) $\left.\left(U_{j}^{k}(t)\right)_{t}^{(l)}\right|_{t=0}=\mathbb{O}$ for $k \neq l$;

(iv) $\left.\left(U_{j}^{k}(t)\right)_{t}^{(k)}\right|_{t=0}=P_{j}$.

Introduce the subspaces $\mathfrak{U}^{1 j}=\operatorname{im} P_{j}$ and $\mathfrak{F}^{1 j}=\operatorname{im} Q_{j}$ for $j=\overline{0, m}$. By construction,

$$
\mathfrak{U}^{1}=\bigoplus_{j=0}^{m} \mathfrak{U}^{1 j} \text { and } \mathfrak{F}^{1}=\bigoplus_{j=0}^{m} \mathfrak{F}^{1 j}
$$

Denote by $A_{1 j}$ the restriction of $A$ to $\mathfrak{U}^{1 j}$ and by $B_{1 j}$ the restriction of $B$ to $\mathfrak{U}^{1 j}$ for $j=\overline{0, m}$.

Theorem 1. [29] (generalized spectral theorem) Suppose that $A, B \in \mathcal{L}(\mathfrak{U} ; \mathfrak{F})$, the operator $B$ is $(A, \sigma)$-bounded, and condition $(A)$ is satisfied then

(i) $A_{1 j} \in \mathcal{L}\left(\mathfrak{U}^{1 j} ; \mathfrak{F}^{1 j}\right)$ and $B_{1 j} \in \mathcal{L}\left(\mathfrak{U}^{1 j} ; \mathfrak{F}^{1 j}\right)$ for $j=\overline{0, m}$;

(ii) the operators $A_{1 j}^{-1} \in \mathcal{L}\left(\mathfrak{F}^{1 j} ; \mathfrak{U}^{1 j}\right)$ exist, for $j=\overline{0, m}$.

Theorem 2. [10] If the operator $B$ is $(A, p)$-bounded for $p \in\{0\} \cup \mathbb{N}$ and condition (A) holds then for all $f \in C^{p n+n}(\mathbb{R} ; \mathfrak{F})$ and $u_{j}^{k} \in \mathfrak{U}$, for $j=\overline{0, m}, k=\overline{0, n-1}$, there exists a unique solution to (5), (6) given by

$$
\begin{gathered}
u(t)=-\sum_{q=0}^{p} H^{q} B_{0}^{-1}(\mathbb{I}-Q) f^{(q n)}(t)+ \\
+\sum_{j=0}^{m} \sum_{k=0}^{n-1} U_{j}^{k}\left(t-\tau_{j}\right) u_{j}^{k}+\sum_{j=0}^{m} \int_{\tau_{j}}^{t} U_{j}^{n-1}(t-s) A_{1 j}^{-1} Q_{j} f(s) d s .
\end{gathered}
$$




\section{A Stochastic Linear Sobolev Type Equation of Higher Order with Relatively $p$-Bounded Operators}

For a real separable Hilbert space $\mathfrak{U} \equiv(\mathfrak{U},\langle\cdot, \cdot\rangle)$, take an operator $K \in \mathcal{L}(\mathfrak{U})$ whose spectrum $\sigma(K)$ is nonnegative, discrete, finite, and accumulates only to zero. Denote by $\left\{\lambda_{j}\right\}$ the sequence of eigenvalues of $K$ enumerated in the non-increasing order taking into account the multiplicities. The linear span of the set $\left\{\varphi_{j}\right\}$ of corresponding orthonormal eigenfunctions of $K$ is dense in $\mathfrak{U}$. Assume also that $K$ is a nuclear operator, that is, its trace $\operatorname{Tr} K=\sum_{j=1}^{\infty} \lambda_{j}<+\infty$.

Take a sequence $\left\{\eta_{j}\right\}$ of independent stochastic processes $\eta_{j}: \Omega \times \mathcal{I} \rightarrow \mathbb{R}$, a complete probability space $\Omega$, and an interval $\mathcal{I} \subset \mathbb{R}$. Equip $\mathbb{R}$ with the Borel $\sigma$-algebra. Assume that the random variables $\eta_{j}(\omega, t) \in \mathbf{L}_{2}$ are Gaussian for all $\omega \in \mathcal{A}$ and $t \in \mathcal{I}$, where $\mathcal{A}$ is a $\sigma$-algebra on $\Omega$. In addition, the sample trajectory $\eta_{j}(\omega, \cdot)$ is almost surely continuous, that is, $\eta_{j} \in \mathbf{C L}_{2}$ (for a detailed description of the spaces $\mathbf{C}^{l} \mathbf{L}_{2}$ for $l \in\{0\} \cup \mathbb{N}$, see [23]). Define the $\mathfrak{U}$-valued stochastic $K$-process

$$
\Theta_{K}(t)=\sum_{j=1}^{\infty} \sqrt{\lambda_{j}} \eta_{j}(t) \varphi_{j}
$$

assuming that series (8) converges uniformly on every compact subset of $\mathcal{I}$. Observe that if $\left\{\eta_{j}\right\} \subset \mathbf{C L}_{2}$ then the existence of a stochastic $K$-process $\Theta_{K}$ implies that its trajectories are almost surely (a.s.) continuous. Introduce the Nelson-Gliklikh derivatives

$$
\stackrel{\circ}{\Theta}_{K}^{(l)}(t)=\sum_{j=1}^{\infty} \sqrt{\lambda_{j}} \stackrel{\circ}{\eta}_{j}^{(l)}(t) \varphi_{j}
$$

of the stochastic $K$-process assuming that the derivatives in the right-hand side up to order $l$ exist and all series converge uniformly on every compact subset of $\mathcal{I}$. (For a detailed description of the Nelson-Gliklikh derivative, see [15, 23]). Introduce [23] the space of differentiable "noises" $\mathbf{C}_{K}^{l} \mathbf{L}_{2}$ of stochastic $K$-processes whose trajectories are a.s. continuously differentiable on $\mathcal{I}$ in the sense of Nelson-Gliklikh up to order $l \in\{0\} \cup \mathbb{N}$.

As an example, let us present "black noise", a stochastic $K$-process whose trajectories a.s. coincide with zero (that is, absolute silence), as well as "white noise"

$$
\stackrel{\circ}{W_{K}}(t)=\frac{W_{K}(t)}{2 t}
$$

which is the Nelson-Gliklikh derivative of the Wiener $K$-process

$$
W_{K}(t)=\sum_{j=1}^{\infty} \sqrt{\lambda_{j}} \beta_{j}(t) \varphi_{j}, \quad t \in \overline{\mathbb{R}}_{+} .
$$

Here $\beta_{j}=\beta_{j}(t)$ is the Brownian motion of the form

$$
\beta_{j}(t)=\sum_{k=1}^{\infty} \xi_{j k} \sin \frac{\pi(2 k+1)}{2} t, t \in \overline{\mathbb{R}}_{+},
$$


where $\xi_{j k}$ are pairwise independent Gaussian random variables such that $\mathbf{E} \xi_{j k}=0$ and $\mathbf{D} \xi_{j k}=\left[\frac{\pi(2 k+1)}{2}\right]^{-2}$, that is, $\xi_{j k} \in \mathbf{L}_{2}$.

Having considered the deterministic equation (5) in the previous section, we now proceed to the stochastic equation (3). Assume that the operator $B$ is $(A, p)$-bounded, with $p \in\{0\} \cup \mathbb{N}$, and condition (A) is satisfied. Consider the linear stochastic Sobolev type equation

$$
A \stackrel{\circ}{\eta}=B \eta+N w
$$

where $\eta=\eta(t)$ is the required stochastic $K$-process, $\stackrel{(n)}{\eta}^{\text {is }}$ its Nelson-Gliklikh derivative of the $n$-th order, $w=w(t)$ is a known stochastic $K$-process, and the operator $N$ is defined below.

Take $\tau_{0}=0$ and $\tau_{j} \in \mathbb{R}_{+}$with $\tau_{j-1}<\tau_{j}$ for $j=\overline{1, m}$. Complement (11) with the multipoint initial-final conditions

$$
P_{j}\left(\stackrel{\circ}{\eta}^{(k)}\left(\tau_{j}\right)-\xi_{j}^{k}\right)=0, \quad j=\overline{0, m}, k=\overline{0, n-1},
$$

where $P_{j}$ are the relatively spectral projectors from Lemma 3 . In view of (10), we also have to consider the weak (in the sense of S. Krein) multipoint initial-final conditions

$$
\lim _{t \rightarrow \tau_{0}+} P_{0}\left(\eta^{(k)}(t)-\xi_{0}^{k}\right)=0, \quad P_{j}\left(\eta^{(k)}\left(\tau_{j}\right)-\xi_{j}^{k}\right)=0, \quad j=\overline{1, m}, k=\overline{0, n-1} .
$$

Here

$$
\xi_{j}^{k}=\sum_{i=1}^{\infty} \sqrt{\lambda_{k}} \xi_{j i}^{k} \varphi_{k}, j=\overline{0, m}, k=\overline{0, n-1},
$$

$\xi_{j i}^{k} \in \mathbf{L}_{2}$ is a Gaussian random variable such that series (14) converges. (For instance $D \xi_{j i}^{k} \leq C_{j}^{k}, i \in \mathbb{N}, j=\overline{0, m}, k=\overline{0, n-1}$ ). Call a stochastic $K$-process $\eta \in \mathbf{C}_{K}^{n} \mathbf{L}_{2}$ a (classical) solution to (11) whenever a.s. all its trajectories satisfy (11) for some stochastic $K$-process $w \in \mathbf{C}_{K} \mathbf{L}_{2}$, some operator $N \in \mathcal{L}(\mathcal{U} ; \mathcal{F})$, and all $t \in \mathcal{I}$. (Here and henceforth $\mathcal{I}=(0,+\infty))$. Call a solution $\eta=\eta(t)$ to (11) a (classical) solution to problem (11), (12) (problem (11), (13)) whenever in addition condition (12) (condition (13)) is satisfied.

Theorem 3. For $p \in\{0\} \cup \mathbb{N}$ take an $(A, p)$-bounded operator $B$ and assume that condition (A) holds. Given $\tau_{j} \in \mathbb{R}_{+}$for $j=\overline{1, m}$, an operator $N \in \mathcal{L}(\mathfrak{U} ; \mathfrak{F})$, a nuclear operator $K \in \mathcal{L}(\mathfrak{U})$ with real spectrum $\sigma(K)$, a stochastic $K$-process $w=w(t)$ such that $(\mathbf{I}-Q) N w \in \mathbf{C}_{K}^{p n+n} \mathbf{L}_{2}$ and $Q N w \in \mathbf{C}_{K} \mathbf{L}_{2}$, and random variables $\xi_{j}^{k} \in \mathbf{L}_{2}$, for $j=\overline{0, m} k=\overline{0, n-1}$, such that (14) is fulfilled, there exists a unique solution $\eta \in \mathbf{C}_{K}^{n} \mathbf{L}_{2}$ to problem (11), (12) given by

$$
\begin{gathered}
\eta(t)=-\sum_{q=0}^{p} H^{q} B_{0}^{-1}(\mathbb{I}-Q) \stackrel{\circ}{w^{(q n)}(t)+} \\
+\sum_{j=0}^{m}\left[\sum_{k=0}^{n-1} U_{j}^{k}\left(t-\tau_{j}\right) \xi_{j}^{k}+\int_{\tau_{j}}^{t} U_{j}^{n-1}(t-s) A_{1 j}^{-1} Q_{j} w(s) d s\right], \quad t \in \mathcal{I} .
\end{gathered}
$$


Let us sketch the proof. It is straight forward to verify that (17) is a solution to problem (11), (12). To establish the uniqueness, reduce the problem to the equivalent system

$$
A \stackrel{\circ}{\eta}^{(n)}=B \eta, P_{j} \stackrel{\circ}{\eta}^{(k)}\left(\tau_{j}\right)=0, j=\overline{0, m}, k=\overline{0, n-1} .
$$

By Theorem 1 the first equation here is equivalent to the system

$$
H\left(\stackrel{\circ}{\eta}^{0}\right)^{(n)}=\eta^{0},\left(\stackrel{\circ}{\eta}^{1}\right)^{(n)}=S \eta^{1}
$$

where $\eta^{0}=(\mathbf{I}-P) \eta$ and $\eta^{1}=P \eta$. Taking now the $n$-th Nelson-Gliklikh derivative of the first equation and acting on the left by $H$ we obtain in succession

$$
0=H^{p+1}\left(\stackrel{\circ}{\eta}^{0}\right)^{(n p+n)}=\ldots=H^{2}\left(\stackrel{\circ}{\eta}^{0}\right)^{(2 n)}=\ldots=H\left(\stackrel{\circ}{\eta}^{0}\right)^{(n)}=\eta^{0}
$$

By Theorem 2 and the initial-final conditions (12), the second equation of (16) yields $\eta^{1}=\sum_{j=0}^{m} \sum_{k=0}^{n-1} U_{j}^{k}\left(t-\tau_{j}\right) 0=0$.

In view of (10), problem (11), (12) is not solvable when the right-hand side of (11) is the "white noise" $w(t)=\stackrel{\circ}{W}_{K}(t)$. In this case instead of conditions (12) we should consider conditions (13).

Corollary 1. If all conditions of Theorem 3 hold and $w(t)=\stackrel{\circ}{W}_{K}(t)$ then, for random variables $\xi_{j}^{k} \in \mathbf{L}_{2}$ given by (14) there exists a unique solution to problem (11), (13) given by

$$
\begin{gathered}
\eta(t)=-\sum_{q=0}^{p} H^{q} B_{0}^{-1}(\mathbb{I}-Q) \stackrel{\circ}{W}_{K}^{(q n+1)}(t)+ \\
+\sum_{j=0}^{m}\left[\sum_{k=0}^{n-1} U_{j}^{k}\left(t-\tau_{j}\right) \xi_{j}^{k}-U_{j}^{n-1}\left(t-\tau_{j}\right) A_{1 j}^{-1} Q_{j} N W_{K}\left(\tau_{j}\right)+\right. \\
\left.+\int_{\tau_{j}}^{t} U_{j}^{n-2}(t-s) A_{1 j}^{-1} Q_{j} N W_{K}(s) d s\right], \quad t \in \mathcal{I} .
\end{gathered}
$$

The proof of Corollary 1 is similar to that of Theorem 3. The difference in the additive terms is caused by an application of integration "by parts",

$$
\begin{gathered}
\int_{\tau_{j}}^{t} U_{j}^{n-1}(t-s) A_{1 j}^{-1} Q_{j} N \stackrel{\circ}{W}{ }_{K}(s) d s= \\
-U_{j}^{n-1}\left(t-\tau_{j}\right) A_{1 j}^{-1} Q_{j} N W_{K}\left(\tau_{j}\right)+\int_{\tau_{j}}^{t} U_{j}^{n-2}(t-s) A_{1 j}^{-1} Q_{j} N W_{K}(s) d s,
\end{gathered}
$$

which follows from the properties of the Nelson-Gliklikh derivative. 


\section{The Multipoint Initial-Final Problem for the Stochastic Boussinesq-Love Equation with Additive "White Noise"}

Let $D \subset \mathbb{R}^{d}$ be a bounded domain with the boundary $\partial D$ of class $C^{\infty}$. Fix $l \in\{0\} \cup \mathbb{N}$ and set $\mathfrak{F}=W_{2}^{l}(D), \mathfrak{U}=\left\{u \in W_{2}^{l+2}(D): u(x)=0, x \in \partial D\right\}$. Obviously, $\mathfrak{U}$ is a real separable Hilbert space densely and continuously embedded in $\mathfrak{F}$.

Let $\left\{\nu_{j}\right\}$ be the sequence of eigenvalues of the Laplace operator with homogenous Dirichlet boundary conditions, numbered in nondecreasing order according to multiplicity, and by $\left\{\varphi_{j}\right\}$ denote the set of corresponding eigenfunctions, orthonormal in the sense of $\mathfrak{F}$.

Introduce the $\mathfrak{U}$-valued random $K$-processes. Construct the operator $\Lambda=(-1)^{m-1} \Delta^{m}$ with domain $\operatorname{dom} \Lambda=\left\{W_{2}^{l+2(m+1)}(D): \Delta^{k} u(x)=0, x \in \partial D, k=\right.$ $0,1, \ldots, m-1\}, m \in \mathbb{N}$. Note that the operator $\Lambda$ has the same eigenfunctions $\left\{\varphi_{j}\right\}$, as the Laplace operator, but its spectrum consists of eigenvalues $\left|\nu_{j}\right|^{m}$. Since their asymptotic $\left|\nu_{j}\right|^{m} \sim j^{\frac{2 m}{d}} \rightarrow \infty, j \rightarrow \infty$, we consider such number $m \in \mathbb{N}$ for a fixed $d \in \mathbb{N}$ that the

series $\sum_{j=1}^{\infty}\left|\nu_{j}\right|^{-m}$ converges (in particular $m=d$ ). Then the operator $\Lambda$ is continuously invertible on $\mathfrak{U}$, whereas the inverse operator (i.e. the Green operator) has a spectrum consisting of eigenvalues $\lambda_{j}=\left|\nu_{j}\right|^{-m}$. We take that very operator as the nuclear operator $K$ and consider the Wiener $K$-process

$$
W_{K}(t)=\sum_{j: \nu_{j} \neq \lambda}^{\infty} \sqrt{\lambda_{j}} \beta_{j}(t) \varphi_{j} .
$$

In the cylinder $D \times[0, T], T \in \mathbb{R}_{+}$consider the Dirichlet problem

$$
\xi(x, t)=0, \quad(x, t) \in \partial D \times[0, T]
$$

for the equation

$$
\left(\lambda-\Delta_{x}\right) \stackrel{o}{\xi} t=\alpha \Delta_{x} \xi+\stackrel{o}{W}{ }_{K} .
$$

Put $A=\lambda-\Delta_{x}, B=\alpha \Delta_{x}, N=\mathbb{I}$.

Lemma 4. [10] For all $\alpha \in \mathbb{R}_{+}, \lambda \in \mathbb{R}$ the operator $B$ is $(A, 0)$-bounded.

In order to state initial-final conditions, we need relatively spectral projectors. In this example for the sake of simplicity we confine to three initial-final conditions. First of all present the projectors

$$
P(Q)=\left\{\begin{array}{c}
\mathbf{I}_{\mathfrak{U}}\left(\mathbf{I}_{\mathfrak{F}}\right) \text { if } \lambda \neq \nu_{j} \text { for all } j \in \mathbb{N} \\
\mathbf{I}_{\mathfrak{U}}-\sum_{\lambda=\nu_{j}}\left\langle\cdot, \varphi_{j}\right\rangle_{\mathfrak{U}} \varphi_{j}\left(\mathbf{I}_{\mathfrak{F}}-\sum_{\lambda=\nu_{j}}\left\langle\cdot, \varphi_{j}\right\rangle_{\mathfrak{F}} \varphi_{j}\right) .
\end{array}\right.
$$

Furthermore, choose $h_{1}, h_{2} \in \mathbb{R}_{+}$such that $h_{1}<h_{2}$ and the sets $\sigma_{0}^{A}(B)=\left\{\mu_{j} \in \sigma^{A}(B)\right.$ : $\left.\left|\mu_{j}\right| \leq h_{1}\right\}, \sigma_{1}^{A}(B)=\left\{\mu_{j} \in \sigma^{A}(B): h_{1}<\left|\mu_{j}\right| \leq h_{2}\right\}$, and $\sigma_{2}^{A}(B)=\left\{\mu_{j} \in \sigma^{A}(B):\left|\mu_{j}\right|>\right.$ $\left.h_{2}\right\}$ are not empty; hence, $\sigma_{0}^{A}(B) \cap \sigma_{1}^{A}(B) \cap \sigma_{1}^{A}(B)=\emptyset$ and condition $(A)$ holds. 
Construct the projectors

$$
\begin{aligned}
& P_{1}=\mathbf{I}_{\mathfrak{U}}-\sum_{h_{1}<\left|\mu_{j}\right| \leq h_{2}}\left\langle\cdot, \varphi_{j}\right\rangle_{\mathfrak{U}} \varphi_{j}, P_{2}=\mathbf{I}_{\mathfrak{U}}-\sum_{h_{2}<\left|\mu_{j}\right|}\left\langle\cdot, \varphi_{j}\right\rangle_{\mathfrak{U}} \varphi_{j}, \\
& Q_{1}=\mathbf{I}_{\mathfrak{F}}-\sum_{h_{1}<\left|\mu_{j}\right| \leq h_{2}}\left\langle\cdot, \varphi_{j}\right\rangle_{\mathfrak{F}} \varphi_{j}, Q_{2}=\mathbf{I}_{\mathfrak{F}}-\sum_{h_{2}<\left|\mu_{j}\right|}\left\langle\cdot, \varphi_{j}\right\rangle_{\mathfrak{F}} \varphi_{j} \text {, } \\
& P_{0}=P-P_{1}-P_{2}, Q_{0}=Q-Q_{1}-Q_{2} .
\end{aligned}
$$

Finally, choose $\tau_{1} \in(0, T)$ as well as random variables $\xi_{0}, \xi_{1}$ and $\xi_{2}$ independent of each other and of stochastic $K$-processes $\stackrel{\circ}{W}_{K}$ and pose the initial-final conditions

$$
\begin{gathered}
\lim _{t \rightarrow 0+} P_{0}\left(\eta(t)-\xi_{0}\right)=0, \\
P_{1}\left(\eta\left(\tau_{1}\right)-\xi_{1}\right)=0, P_{2}\left(\eta(T)-\xi_{2}\right)=0,
\end{gathered}
$$

where

$$
\xi_{0}=\sum_{i=1}^{\infty} \sqrt{\lambda_{i}} \xi_{0 i} \varphi_{i}, \quad \xi_{1}=\sum_{i=1}^{\infty} \sqrt{\lambda_{i}} \xi_{1 i} \varphi_{i}, \quad \xi_{2}=\sum_{i=1}^{\infty} \sqrt{\lambda_{i}} \xi_{2 i} \varphi_{i}
$$

Applying the results of Section 2 to problem (18), (19), (21), we obtain the following theorem.

Theorem 4. For all numbers $\lambda \in \mathbb{R}, \alpha \in \mathbb{R} \backslash\{0\}$ and $\tau_{1} \in(0, T)$, as well as random variables $\xi_{0 i}$, $\xi_{1 i}$ and $\xi_{2 i}$ such that $D \xi_{j i} \leq C_{j}$ for $i \in \mathbb{N}, j=0,1,2$ for some $C_{j} \in \mathbb{R}_{+}$there exists a unique solution $\eta=\eta(t)$, for $t \in \mathbb{R}_{+}$, to problem (18), (19), (21) given by

$$
\begin{gathered}
\eta(t)=-B_{0}^{-1}(\mathbf{I}-Q) \stackrel{\circ}{W_{K}}(t)+U_{0}^{0}(t) \xi_{0}^{0}+U_{0}^{1}(t) \xi_{0}^{1}+ \\
+\int_{0}^{t} U_{0}^{0}(t-s) A_{10}^{-1} Q_{0} W_{K}(s) d s+U_{1}^{0}\left(t-\tau_{1}\right) \xi_{1}^{0}+U_{1}^{1}\left(t-\tau_{1}\right) \xi_{1}^{1}- \\
-U_{1}^{1}\left(t-\tau_{1}\right) A_{11}^{-1} Q_{1} W_{K}\left(\tau_{1}\right)+\int_{\tau_{1}}^{t} U_{1}^{0}(t-s) A_{11}^{-1} Q_{1} W_{K}(s) d s+ \\
+U_{2}^{0}(t-T) \xi_{2}^{0}+U_{2}^{1}(t-T) \xi_{2}^{1}-U_{2}^{1}(t-T) A_{12}^{-1} Q_{2} W_{K}(T)+ \\
+\int_{T}^{t} U_{2}^{0}(t-s) A_{12}^{-1} Q_{2} W_{K}(s) d s, t \in \mathbb{R}_{+} .
\end{gathered}
$$

Here

$$
\begin{gathered}
B_{0}^{-1}=\frac{1}{\alpha \lambda} \sum_{\nu_{k}=\lambda}\left\langle\cdot, \varphi_{k}\right\rangle \varphi_{k}, \\
U_{0}^{0}(t)=\sum_{\substack{\mu_{k} \in \sigma_{0}^{A}(B), \lambda<\nu_{k}}}\left\langle\cdot, \varphi_{k}\right\rangle \varphi_{k} \operatorname{ch} \sqrt{\frac{\alpha \nu_{k}}{\lambda-\nu_{k}}} t+\sum_{\substack{\mu_{k} \in \sigma_{0}^{A}(B), \lambda>\nu_{k}}}\left\langle\cdot, \varphi_{k}\right\rangle \varphi_{k} \cos \sqrt{\frac{\alpha \nu_{k}}{\nu_{k}-\lambda}} t, \\
U_{0}^{1}(t)=\sum_{\substack{\mu_{k} \in \sigma_{0}^{A}(B), \lambda<\nu_{k}}}\left\langle\cdot, \varphi_{k}\right\rangle \varphi_{k} \sqrt{\frac{\lambda-\nu_{k}}{\alpha \nu_{k}}} \operatorname{sh} \sqrt{\frac{\alpha \nu_{k}}{\lambda-\nu_{k}}} t+\sum_{\substack{\mu_{k} \in \sigma_{0}^{A}(B), \lambda>\nu_{k}}}\left\langle\cdot, \varphi_{k}\right\rangle \varphi_{k} \sqrt{\frac{\nu_{k}-\lambda}{\alpha \nu_{k}}} \sin \sqrt{\frac{\alpha \nu_{k}}{\nu_{k}-\lambda}} t,
\end{gathered}
$$




$$
\begin{aligned}
& A_{10}^{-1}=\sum_{\mu_{k} \in \sigma_{0}^{A}(B)}\left(\lambda-\nu_{k}\right)^{-1}\left\langle\cdot, \varphi_{k}\right\rangle \varphi_{k} \\
& U_{1}^{0}(t)=\sum_{\mu_{k} \in \sigma_{1}^{A}(B),}\left\langle\cdot, \varphi_{k}\right\rangle \varphi_{k} \operatorname{ch} \sqrt{\frac{\alpha \nu_{k}}{\lambda-\nu_{k}}} t+\sum_{\mu_{k} \in \sigma_{1}^{A}(B),}\left\langle\cdot, \varphi_{k}\right\rangle \varphi_{k} \cos \sqrt{\frac{\alpha \nu_{k}}{\nu_{k}-\lambda}} t, \\
& \lambda<\nu_{k} \quad \lambda>\nu_{k} \\
& U_{1}^{1}(t)=\sum_{\substack{\mu_{k} \in \sigma_{1}^{A}(B), \lambda<\nu_{k}}}\left\langle\cdot, \varphi_{k}\right\rangle \varphi_{k} \sqrt{\frac{\lambda-\nu_{k}}{\alpha \nu_{k}}} \operatorname{sh} \sqrt{\frac{\alpha \nu_{k}}{\lambda-\nu_{k}}} t+\sum_{\substack{\mu_{k} \in \sigma_{1}^{A}(B), \lambda>\nu_{k}}}\left\langle\cdot, \varphi_{k}\right\rangle \varphi_{k} \sqrt{\frac{\nu_{k}-\lambda}{\alpha \nu_{k}}} \sin \sqrt{\frac{\alpha \nu_{k}}{\nu_{k}-\lambda}} t, \\
& A_{11}^{-1}=\sum_{\mu_{k} \in \sigma_{1}^{A}(B)}\left(\lambda-\nu_{k}\right)^{-1}\left\langle\cdot, \varphi_{k}\right\rangle \varphi_{k} \\
& U_{2}^{0}(t)=\sum_{\substack{\mu_{k} \in \sigma_{2}^{A}(B), \lambda<\nu_{k}}}\left\langle\cdot, \varphi_{k}\right\rangle \varphi_{k} \operatorname{ch} \sqrt{\frac{\alpha \nu_{k}}{\lambda-\nu_{k}}} t+\sum_{\substack{\mu_{k} \in \sigma_{2}^{A}(B), \lambda>\nu_{k}}}\left\langle\cdot, \varphi_{k}\right\rangle \varphi_{k} \cos \sqrt{\frac{\alpha \nu_{k}}{\nu_{k}-\lambda}} t, \\
& U_{2}^{1}(t)=\sum_{\substack{\mu_{k} \in \sigma_{2}^{A}(B), \lambda<\nu_{k}}}\left\langle\cdot, \varphi_{k}\right\rangle \varphi_{k} \sqrt{\frac{\lambda-\nu_{k}}{\alpha \nu_{k}}} \operatorname{sh} \sqrt{\frac{\alpha \nu_{k}}{\lambda-\nu_{k}}} t+\sum_{\substack{\mu_{k} \in \sigma_{2}^{A}(B), \lambda>\nu_{k}}}\left\langle\cdot, \varphi_{k}\right\rangle \varphi_{k} \sqrt{\frac{\nu_{k}-\lambda}{\alpha \nu_{k}}} \sin \sqrt{\frac{\alpha \nu_{k}}{\nu_{k}-\lambda}} t, \\
& A_{12}^{-1}=\sum_{\mu_{k} \in \sigma_{2}^{A}(B)}\left(\lambda-\nu_{k}\right)^{-1}\left\langle\cdot, \varphi_{k}\right\rangle \varphi_{k} .
\end{aligned}
$$

\section{Conclusion}

The next stage of our studies is to spread the ideas and the developed methods of the theory of multipoint initial-final problems for linear Sobolev type equations of higher order from the relatively $p$-bounded to the relatively $(n, p)$-sectorial case and to the case of complete higher order Sobolev type equations with initial-final conditions. In addition, it would be interesting to apply these ideas to inverse problems for Sobolev type equations of higher order.

Acknowledgement. The work was supported by Act 211 Government of the Russian Federation, contract no. 02.A03.21.0011.

\section{References}

1. Demidenko G.V., Uspenskii S.V. Partial Differential Equations and Systems Not Solvable with Respect to the Highest Order Derivative. N.Y., Basel, Hong Kong, Marcel Dekker, Inc., 2003.

2. Al'shin A.B., Korpusov M.O., Sveshnikov A.G. Blow-up in Nonlinear Sobolev Type Equations. De Gruyter, 2011.

3. Favini A., Yagi A. Degenerate Differential Equations in Banach Spaces. N.Y., Basel, Hong Kong, Marcel Dekker, Inc., 1999. 
4. Kozhanov A.I. Boundary Problems for Odd Ordered Equations of Mathematical Physics. Novosibirsk, NGU, 1990.

5. Showalter R.E. Hilbert Space Methods for Partial Differential Equations. Pitman, London, San Francisco, Melbourne, 1977.

6. Sidorov N., Loginov B., Sinithyn A., Falaleev M. Lyapunov-Shmidt Methods in Nonlinear Analysis and Applications. Dordrecht, Boston, London, Kluwer Academic Publishers, 2002.

7. Sviridyuk G.A., Fedorov V.E. Linear Sobolev Type Equations and Degenerate Semigroups of Operators. Utrecht, Boston, Köln, Tokyo, VSP, 2003.

8. Zamyshlyaeva A.A., Sviridyuk G.A. The Linearized Benney-Luke Mathematical Model with Additive White Noise. Springer Proceedings in Mathematics and Statistics, 2015, vol. 113, pp. 327-337. DOI: 10.1007 / 978-3-319-12145-1_21

9. Bychkov E.V. On a Semilinear Sobolev-Type Mathematical Model. Bulletin of the South Ural State University. Series: Mathematical Modelling, Programming and Computer Software, 2014, vol. 7 , no. 2, pp. 111-117. DOI: $10.14529 / \mathrm{mmp} 140210$

10. Zamyshlyaeva A.A. The Higher Order Sobolev Type Models. Bulletin of the South Ural State University. Series: Mathematical Modelling, Programming and Computer Software, 2014, vol. 7 , no. 2, pp. 5-28. DOI: 10.14529/mmp140201

11. Melnikova I.V., Filinkov A.I., Alshansky M.A. Abstract Stochastic Equations II. Solutions in Spaces of Abstract Stochastic Distributions. Journal of Mathematical Sciences, 2003, vol. 116, no. 5 , pp. $3620-3656$.

12. Wang S., Chen G. Small Amplitude Solutions of the Generalized IMBq Equation. Mathematical Analysis and Applications, 2002, vol. 274, pp. 846-866.

13. Whitham G.B. Linear and Nonlinear Waves. N.Y., Wiley, 1974.

14. Landau L.D., Lifshits E.M. Teoreticheskaya fizika. T 7. Teoriya uprugosti [Theoretical Phisics, VII. Elasticity Theory]. Moscow, Nauka, 1987. (in Russian)

15. Gliklikh Yu.E. Global and Stochastic Analysis with Applications to Mathematical Physics. London, Dordrecht, Heidelberg, N.Y., Springer, 2011.

16. Gliklikh Yu.E., Mashkov E.Yu. Stochastic Leontieff Type Equations and Mean Derivatives of Stochastic Processes. Bulletin of the South Ural State University. Series: Mathematical Modelling, Programming and Computer Software, 2013, vol. 6, no. 2, pp. 25-39.

17. Zagrebina S.A., Soldatova E.A., Sviridyuk G.A. The Stochastic Linear Oskolkov Model of the Oil Transportation by the Pipeline. Springer Proceedings in Mathematics and Statistics, 2015, vol. 113, pp. 317-325. DOI: 10.1007/978-3-319-12145-1-20

18. Da Prato G., Zabczyk J. Stochastic Equations in Infinite Dimensions of Encyclopedia of Mathematics and Its Applications, 44. Cambridge, Cambridge University Press, 1992.

19. Arato M. Linear Stochastic Systems with Constant Coefficients. A Statistical Approach 45 of Lecture Notes in Control and Information Sciences, Berlin, Springer, 1982.

20. Kovács M., Larsson S. Introduction to Stochastic Partial Differential Equations. Proceedings of "New Directions in the Mathematical and Computer Sciences", National Universities Commission, Abuja, Nigeria, October 8-12, 200\%, Publications of the ICMCS, 2008, vol. 4, pp. 159-232.

21. Favini A., Sviridyuk G., Manakova N. Linear Sobolev Type Equations with Relatively $p$ Sectorial Operators in Space of "Noises". Abstract and Applied Analysis, 2015, vol. 2015, Article ID 697410, 8 p. 
22. Favini A., Sviridyuk G., Sagadeeva M., Linear Sobolev Type Equations with Relatively pRadial Operators in Space of "Noises". Mediterranean Journal of Mathematics, 2016, vol. 13, no. 6, pp. 4607-4621. DOI: 10.1007/s00009-016-0765-x

23. Favini A., Sviridyuk G.A., Zamyshlyaeva A.A. One Class of Sobolev Type Equations of Higher Order with Additive "White Noise". Communications on Pure and Applied Analysis, 2014, vol. 15 , no. 1 , pp. 185-196. DOI: $10.3934 /$ cpaa.2016.15.185

24. Nelson E. Dynamical Theories of Brownian Motion. Princeton, Princeton University Press, 1967.

25. Shestakov A.L., Keller A.V., Nazarova E.I. Numerical Solution of the Optimal Measurement Problem. Automation and Remote Control, 2012, vol. 73, no. 1, pp. 97-104.

26. Keller A.V., Sagadeeva M.A. The Optimal Measurement Problem for the Measurement Transducer Model with a Deterministic Multiplicative Effect and Inertia. Bulletin of the South Ural State University. Series: Mathematical Modelling, Programming and Computer Software, 2014, vol. 7, no. 1, pp. 134-138. DOI: 10.14529/mmp140111

27. Konkina A.S. Multipoint Initial-Final Value Problem for the Model of Devis with Additive White Noise. Bulletin of the South Ural State University. Series: Mathematical Modelling, Programming and Computer Software, 2017, vol. 10, no. 2, pp. 144-149. DOI: $10.14529 / \mathrm{mmp} 170212$

28. Manakova N.A. Mathematical Models and Optimal Control of the Filtration and Deformation Processes. Bulletin of the South Ural State University. Series: Mathematical Modelling, Programming and Computer Software, 2015, vol. 8, no. 3, pp. 5-24. DOI: $10.14529 / \mathrm{mmp} 150301$

29. Zagrebina S.A. A Multipoint Initial-Final Value Problem for a Linear Model of Plane-Parallel Thermal Convection in Viscoelastic Incompressible Fluid. Bulletin of the South Ural State University. Series: Mathematical Modelling, Programming and Computer Software, 2014, vol. 7 , no. 3, pp. 5-22. DOI:10.14529/mmp140301

Received February 8, 2018

\title{
МНОГОТОЧЕЧНАЯ НАЧАЛЬНО-КОНЕЧНАЯ ЗАДАЧА ДЛЯ ОДНОГО КЛАССА МОДЕЛЕЙ СОБОЛЕВСКОГО ТИПА ВЫСОКОГО ПОРЯДКА С АДДИТИВНЫМ «БЕЛЫМ ШУМОМ»
}

\author{
Г.А. Свиридюк ${ }^{1}$ А.А. Замышляева ${ }^{1}$, С.А. Загребина \\ ${ }^{1}$ Южно-Уральский государственный университет, г. Челябинск, \\ Российская Федерация
}

Теория уравнений Соболева была предметом интереса многих исследователей последние годы, при этом много внимания уделялось детерминированным уравнениям и системам. Тем не менее, существуют также математические модели, содержащие случайные возмущения, такие как белый шум. Новая концепция «белого шума», первоначально построенная для конечномерных пространств, в данной работе распространяется на случай бесконечномерных пространств. Основная цель заключается в 
разработке стохастической теории уравнений соболевского типа высокого порядка и предоставлении некоторых практических приложений. Основная идея состоит в том, чтобы построить пространства «шумов», используя производную Нельсона - Гликлиха. Абстрактные результаты, касающиеся начально-конечных задач для уравнений соболевского типа высокого порядка, применяются к математической модели Буссинеска - Лява с аддитивным «белым шумом». Использован такой известный метод теории уравнений соболевского типа, как метод фазового пространства, заключающийся в редукции сингулярного уравнения к регулярному, определенному на некотором подпространстве исходного пространства, понимаемом как фазовое пространство.

Ключевые слова: уравнение соболевского типа; пропагатор; «белый иум»; винеровский K-процесс; многоточечная начально-конечная задача.

Статъя выполнена при поддержке Правительства РФ (Постановление № 211 oт 16.03.2013 г.), соглашение № 02.A03.21.0011.

\section{Литература}

1. Demidenko, G.V. Partial Differential Equations and Systems Not Solvable with Respect to the Highest Order Derivative / G.V. Demidenko, S.V. Uspenskii. - N.Y.; Basel; Hong Kong: Marcel Dekker, Inc., 2003.

2. Al'shin, A.B. Blow-up in Nonlinear Sobolev Type Equations / A.B. Al'shin, M.O. Korpusov, A.G. Sveshnikov. - De Gruyter, 2011.

3. Favini, A. Degenerate Differential Equations in Banach Spaces / A. Favini, A. Yagi. - N.Y.; Basel; Hong Kong: Marcel Dekker, Inc., 1999.

4. Кожанов, А.И. Краевые задачи для уравнений математической физики нечетного порядка / А.И. Кожанов. - Новосибирск: НГУ, 1990.

5. Showalter, R.E. Hilbert Space Methods for Partial Differential Equations / R.E. Showalter. - Pitman; London; San Francisco; Melbourne, 1977.

6. Lyapunov - Shmidt Methods in Nonlinear Analysis and Applications / N. Sidorov, B. Loginov, A. Sinithyn, M. Falaleev. - Dordrecht; Boston; London: Kluwer Academic Publishers, 2002.

7. Sviridyuk, G.A. Linear Sobolev Type Equations and Degenerate Semigroups of Operators / G.A. Sviridyuk, V.E. Fedorov. - Utrecht; Boston; Köln; Tokyo: VSP, 2003.

8. Zamyshlyaeva, A.A. The Linearized Benney - Luke Mathematical Model with Additive White Noise / A.A. Zamyshlyaeva, G.A. Sviridyuk // Springer Proceedings in Mathematics and Statistics. - 2015. - V. 113. - P. 327-337.

9. Бычков, Е.В. Об одной полулинейной математической модели соболевского типа высокого порядка / Е.В. Бычков // Вестник ЮУрГУ. Серия: Математическое моделирование и программирование. - 2014. - Т. 7, № 2. - С. 25-39.

10. Melnikova, I.V. Abstract Stochastic Equations II. Solutions In Spaces of Abstract Stochastic Distributions / I.V. Melnikova, A.I. Filinkov, M.A. Alshansky // Journal of Mathematical Sciences. - 2003. - V. 116, № 5. - P. 3620-3656.

11. Замышляева, А.А. Математические модели соболевского типа высокого порядка / А.А. Замышляева // Вестник ЮУрГУ. Серия: Математическое моделирование и программирование. - 2014. - Т. 7, № 2. - С. 25-39.

12. Wang, S. Small Amplitude Solutions of the Generalized IMBq Equation / S. Wang, G. Chen // Mathematical Analysis and Applications. - 2002. - V. 274.- P. 846-866. 
13. Уизем, Дж. Линейные и нелинейные волны / Дж. Уизем. - М.: Мир, 1977.

14. Ландау, Л.Д. Теоретическая физика. Т. VII. Теория упругости / Л.Д. Ландау, Е.М. Лифшиц. - М.: Наука, 1987.

15. Gliklikh, Yu.E. Global and Stochastic Analysis with Applications to Mathematical Physics / Yu.E. Gliklikh. - London; Dordrecht; Heidelberg; N.Y.: Springer, 2011.

16. Gliklikh, Yu.E. Stochastic Leontieff Type Equations and Mean Derivatives of Stochastic Processes / Yu.E. Gliklikh, E.Yu. Mashkov // Вестник ЮУрГУ. Серия: Математическое моделирование и программирование. - 2013. - V. 6, № 2. - Р. 25-39.

17. Zagrebina, S.A. The Stochastic Linear Oskolkov Model of the Oil Transportation by the Pipeline / S.A. Zagrebina, E.A. Soldatova, G.A. Sviridyuk // Springer Proceedings in Mathematics and Statistics. - 2015. - V. 113. - P. 317-325.

18. Da Prato, G. Stochastic Equations in Infinite Dimensions of Encyclopedia of Mathematics and Its Applications / G. Da Prato, J. Zabczyk. - Cambridge: Cambridge University Press, 1992.

19. Arato, M. Linear Stochastic Systems with Constant Coefficients / M. Arato. - Berlin: Springer, 1982.

20. Kovács, M. Introduction to Stochastic Partial Differential Equations / M. Kovács, S. Larsson // Proceedings of «New Directions in the Mathematical and Computer Sciences», National Universities Commission, Abuja, Nigeria, October 8-12, 2007. V. 4. - Lagos: Publications of the ICMCS, 2008. - P. 159-232.

21. Favini, A. Linear Sobolev Type Equations with Relatively p-Sectorial Operators in Space of «Noises» // A. Favini, G.A. Sviridyuk, N.A. Manakova // Abstract and Applied Analysis. 2015. - V. 2015. - Article ID 697410. - 8 p.

22. Favini, A. Linear Sobolev Type Equations with Relatively p-Radial Operators in Space of «Noises» / A. Favini, G. Sviridyuk, M. Sagadeeva // Mediterranean Journal of Mathematics. - 2016. - V. 13, № 6. - P. 4607-4621.

23. Favini, A. One Class of Sobolev Type Equations of Higher Order with Additive «White Noise»/ A. Favini, G.A. Sviridyuk, A.A. Zamyshlyaeva // Communications on Pure and Applied Analysis. - 2014. - V. 15, № 1. - P. 185-196.

24. Nelson, E. Dynamical Theories of Brownian Motion / E. Nelson. - Princeton: Princeton University Press, 1967.

25. Shestakov, A.L. Numerical Solution of the Optimal Measurement Problem / A.L. Shestakov, A.V. Keller, E.I. Nazarova // Automation and Remote Control. - 2012. - V. 73, № 1. P. 97-104.

26. Keller, A.V. The Optimal Measurement Problem for the Measurement Transducer Model with a Deterministic Multiplicative Effect and Inertia / A.V. Keller, M.A. Sagadeeva // Вестник ЮУрГУ. Серия: Математическое моделирование и программировние. - 2014. V. 7, № 1. - P. 134-138.

27. Konkina, A.S. Multipoint Initial-Final Value Problem for the Model of Devis with Additive White Noise / A.S. Konkina // Вестник ЮУрГУ. Серия: Математическое моделирование и программировние. - 2017. - V. 10, № 2. - Р. 144-149.

28. Манакова, Н.А. Математические модели и оптимальное управление процессами фильтрации и деформации / Н.А. Манакова // Вестник ЮУрГУ. Серия: Математическое моделирование и программировние. - 2015. - Т. 8, № 3. - С. 5-24. 
29. Zagrebina, S.A. A Multipoint Initial-Final Value Problem for a Linear Model of Plane-Parallel Thermal Convection in Viscoelastic Incompressible Fluid / S.A. Zagrebina // Вестник ЮУрГУ. Серия: Математическое моделирование и программировние. - 2014. - V. 7, № 3. P. $5-22$.

Георгий Анатольевич Свиридюк, доктор физико-математических наук, профессор, кафедра «Уравнения математической физики», Южно-Уральский государственный университет (г. Челябинск, Российская Федерация), sviridyuk@susu.ru.

Алена Александровна Замышляева, доктор физико-математических наук, доцент, кафедра «Прикладная математика и программирование», ЮжноУральский государственный университет (г. Челябинск, Российская Федерация), zamyshliaevaaa@susu.ru.

Софья Александровна Загребина, доктор физико-математических наук, доцент, кафедра «Математическое и компьютерное моделирование», ЮжноУральский государственный университет (г. Челябинск, Российская Федерация), zagrebinasa@susu.ru.

Поступила в редакиию 8 февраля 2018 г. 